\title{
Comparison of Crack Formation in Retrograde Cavities prepared with Ultrasound, Er,Cr:YSGG Laser or Bur: An ex vivo Study
}

\author{
Seda Arslan, Oya Bala, Gizem Berk, Guven Kayaoglu
}

\begin{abstract}
Objective: The aim of this study was to compare the number of crack formation in retrograde cavities after preparation with ultrasound, Er,Cr:YSGG (erbium, chromium:yttrium, scandium, gallium and garnet) laser with different power and frequency settings and bur.
\end{abstract}

Materials and methods: Root canals of 60 extracted human maxillary incisors were prepared, the apices were horizontally cut and class I retrograde cavities were prepared using an ultrasonic unit (group 1), Er,Cr:YSGG laser (group 2: $3.5 \mathrm{~W}$, $30 \mathrm{~Hz}$; group 3: $3.5 \mathrm{~W}, 20 \mathrm{~Hz}$; group 4: $4 \mathrm{~W}, 30 \mathrm{~Hz}$; group 5: $4 \mathrm{~W} 20 \mathrm{~Hz}$ ) or high-speed bur (group 6). Cracks were examined under a stereomicroscope at a magnification of $\times 20$, scored (0 to 3 ) and classified according to their location (cementum, dentin, canal wall). Scanning electron microscopy analysis was also performed.

Results: Greatest number of cracks was found in the cementum, and least on the canal wall. Ultrasonics followed by bur created the greatest number of crack in the dentin. No significant differences were found when groups 2 and 4, 3 and 5, and 2 and 3 were compared at the 3 regions. A significant difference was found between groups 4 and 5 at the dentin region.

Conclusion: The ultrasonic is the most aggressive root-end preparation technique. The most favorable laser setting was the one used in Group 5; and generally it was safer also than the ultrasound and the bur groups.

Keywords: Bur, Crack, Laser, Ultrasonic, Retrograde cavity.

How to cite this article: Arslan S, Bala O, Berk G, Kayaoglu G. Comparison of Crack Formation in Retrograde Cavities prepared with Ultrasound, Er,Cr:YSGG Laser or Bur: An ex vivo Study. J Contemp Dent 2013;3(1):1-6.

Source of support: Nil

Conflict of interest: None declared

\section{INTRODUCTION}

In case of endodontic failure, nonsurgical endodontic retreatment is the first choice to follow. However, some factors, such as file separation, ledge formation, blocked or calcified canals, etc. may limit the success of the endodontic retreatment. In such cases, surgery with a retrograde filling can be the alternative treatment option. Shape of the retrograde cavity preparation and properties of the cavity filling material significantly affects the success of the retrograde treatment. ${ }^{1,2}$

Various instruments are used in the preparation of the retrograde cavity; but most commonly used instrument for this purpose is burs. However, some problems are associated with the use of burs in retrograde cavity preparations. ${ }^{3}$ Emergence of microcracks on the surface of the apical root and formation of smear layer on the surface of the cavity are among these problems. ${ }^{4}$ In addition, it is difficult to prepare a retrograde cavity with sufficient depth and with parallel walls avoiding the risk of perforation. Because of the difficulty and problems encountered during preparation of a retrograde cavity with bur, alternative approaches have been sought. ${ }^{4-7}$

The use of ultrasonic tips is one of the alternatives. Due to the shape of the ultrasonic tip, it provides much easier access and more adequate cavity shape for retrograde cavity preparation. ${ }^{6}$ Also, because of their small diameter and appropriate angle, only a small amount of bone is removed; thus, the traumatic effects are less. ${ }^{8}$ Several studies demonstrated that retrograde cavities prepared with ultrasonic tips are deeper and more conservative and resemble more to the original shape of the canal compared to retrograde cavities prepared with bur. ${ }^{7-9}$ However, as they work with vibration and by contacting the root canal walls, there is still a risk of formation of cracks on the surface of the cavity which may increase the apical leakage in long term. ${ }^{10}$

In recent years, besides ultrasonic tips, lasers are also used as an alternative for retrograde cavity preparation. ${ }^{11}$ Erbium:yttrium, aluminum, garnet (Er:YAG) and erbium chromium:yttrium, scandium, gallium, garnet (Er,Cr:YSGG) lasers are examples to hard tissue lasers; and dental hard tissues can be removed with the use of these lasers without causing damage to the surrounding tissues. ${ }^{12}$ The Er,Cr:YSGG laser, when used with an air/water spray, has been shown to cut enamel, dentin, cementum, and bone efficiently and cleanly. This laser produces microexplosions during tissue ablation, resulting in macroscopic and microscopic irregularities. It causes vaporization of water and other hydrated organic components of the tissue where an internal pressure builds within the tissue until the explosive destruction of inorganic substance occurs before the melting point is reached. ${ }^{13,14} \mathrm{Er}, \mathrm{Cr}$ :YSGG laserirradiated enamel and dentin surfaces show microirregularities and lack of smear layer. ${ }^{12-16}$ It has been reported that the Er,Cr:YSGG laser can be reliably used for 
the purpose of cutting the tip of the root and retrograde cavity preparation during apical surgery. ${ }^{12,13}$

It has been argued that formation of cracks on the surface of the retrograde cavity during root-end cutting preparation may affect the success of the treatment. Many studies have shown that the use of ultrasonic instruments in retrograde cavity preparation causes formation of cracks on the surface of the $\operatorname{root}^{7,8,10,11,17}$ but less crack formation was found for Er,Cr:YSGG laser in comparison to ultrasonics. ${ }^{17,18}$ However, in these studies, effects of different frequencies and power settings of the laser systems on the crack formation have not been investigated. Therefore, in this study Er,Cr:YSGG laser was used with two different power and two different frequency settings during retrograde cavity preparation. The aim of this study was to investigate the effects regarding crack formation on the surface of the apical root of Er,Cr:YSGG laser with different frequency and power settings during root end cavity preparation, and to compare them with the results obtained with ultrasonic retrotips and conventional burs.

\section{MATERIALS AND METHODS}

\section{Sample Preparation}

In this study, 60 human incisor teeth extracted due to prosthetic, orthodontic or periodontal reasons were used. Soft tissue residues on the surface of the teeth were cleaned with a sharp curette. Subsequently, any crack or fracture on the surfaces of the root were examined with a stereomicroscope $(\times 10$ Olympus SZ60, Japan). Teeth with detected cracks and fractures were not included to the study. After this examination, the teeth were kept in $0.9 \%$ physiological saline solution until use.

First, the crowns of the teeth were removed by means of a diamond saw. The remaining roots were standardized to a length of $15 \mathrm{~mm}$. Working length was determined as $0.5 \mathrm{~mm}$ short of the apical foramen. Root canals were prepared according to the manufacturer's recommendation with a crown-down technique using the ProTaper system (Dentsply Maillefer, Ballaigues, Switzerland). The root canals were irrigated with $2 \mathrm{ml}$ of $2.5 \%$ sodium hypochlorite $(\mathrm{NaOCl})$ after each instrument.

After the root canal preparation was completed, $3 \mathrm{~mm}$ from the apical end of the root was cut using a high-speed diamond bur (Diatech Diamant AG, Heerbrugg, Switzerland) perpendicular to the long axis of the root. The roots were kept in distilled water until use.

\section{Retrograde Cavity Preparation}

Sixty prepared roots were divided into 6 groups including 10 roots each. Retrograde class 1 cavities with $3 \mathrm{~mm}$ depth were prepared in these roots.
- Group 1: Class 1 cavities were prepared using an ultrasonic piezoelectric energy-powered device (P-Max Ultrasonic Scaler, Suprasson, Satelec, France) with a special tip (E32D sapphire tip, NSK, Satelec, France). This ultrasonic device works at 85 to 264 volts and $50 / 60 \mathrm{~Hz}$ power. The ultrasonic device was used at the medium-power setting (Power 8) in accordance with the recommendations of the manufacturer. The ultrasonic tip had a $3 \mathrm{~mm}$ length and a $90^{\circ}$ angle.

For all the laser groups, an Er,Cr:YSGG laser (Waterlase MD, Biolase, San Clemente, California, USA) having 2,780 $\mathrm{nm}$ wavelength was used with a $600 \mu \mathrm{m}$ diameter and $6 \mathrm{~mm}$ length fiberoptic tip.

- Group 2: Class 1 cavities were prepared using the Er,Cr:YSGG laser device at $140 \mu$ s pulse length (H mode), $30 \mathrm{~Hz}$ and $3.5 \mathrm{~W}$ with $70 \%$ water and $80 \%$ air.

- Group 3: Class 1 cavities were prepared using the Er,Cr:YSGG laser device at $140 \mu$ s pulse length (H mode), $20 \mathrm{~Hz}$ and $3.5 \mathrm{~W}$ with $70 \%$ water and $80 \%$ air.

- Group 4: Class 1 cavities were prepared using the Er,Cr:YSGG laser device at $140 \mu$ s pulse length (H mode), $30 \mathrm{~Hz}$ and $4 \mathrm{~W}$ with $70 \%$ water and $80 \%$ air.

- Group 5: Class 1 cavities were prepared using the Er,Cr:YSGG laser device at $140 \mu$ s pulse length (H mode), $20 \mathrm{~Hz}$ and $4 \mathrm{~W}$ with $70 \%$ water and $80 \%$ air.

- Group 6: Class 1 cavities were prepared using a stainless steel round bur (DIATECH, Coltene Whaledent, Altstatten, Switzerland) mounted to a traditional highspeed turbine.

In order to ensure that there were no deviations on the depth of the cavities, millimetric-ended periodontal probes were used during preparation.

\section{Observation of Cracks on the Apical Root Surface}

After the retrograde cavities were prepared, all surfaces of the samples were examined under a stereomicroscope at a magnification of $\times 20$ (Wild, Heerbrugg, Switzerland). Cracks were classified according to their location (cementum, dentin, canal wall; Fig. 1) and scored as following:

- Score 0: No crack

- Score 1: 0-5 cracks

- Score 2: 5-10 cracks

- Score 3: More than 10 cracks

In addition, one sample from each group was coated with gold-palladium (20 $\AA$ thickness) and analyzed with scanning electron microscope at a magnification of $\times 25$ (SEM; JSM-840A, JEOL-Technic Co Ltd, Japan; Fig. 2). 
Statistical analysis was performed using SPSS for Windows 11.5 package program (Chicago, IL, USA). Significance of the difference between the groups in terms of crack score values was examined using Kruskal-Wallis and nonparametric multiple comparison tests. The statistical significance was set to $5 \%$.

\section{RESULTS}

Crack scores and their distribution (cementum, dentin or canal wall) have been overviewed in Table 1. Statistical comparisons and significant differences between the groups have been shown in Table 2 .

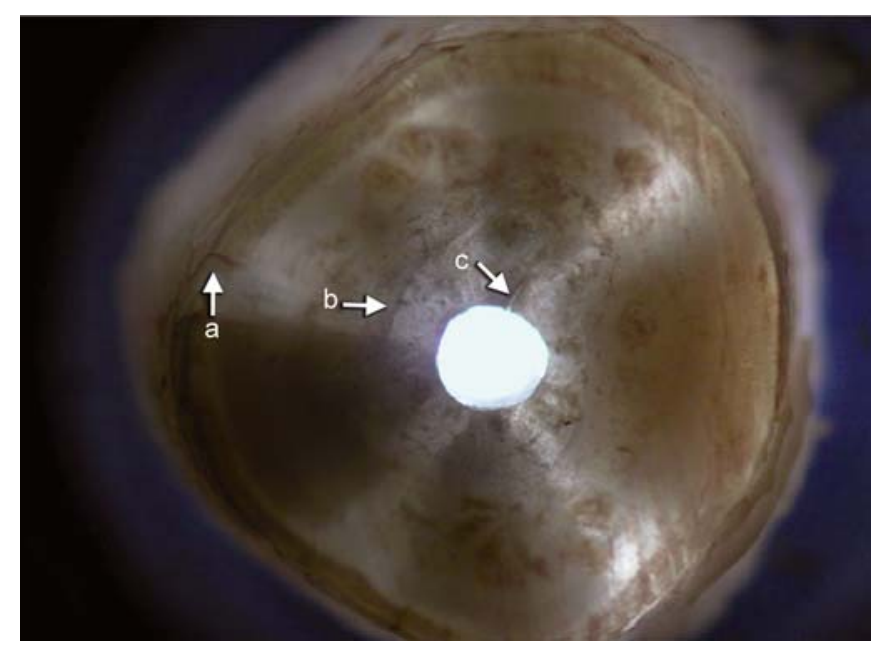

Fig. 1: A representative sample showing a simultaneous cemental crack (a) dentinal crack (b) and a crack along the canal lumen (c) $\times 20$ magnification

\section{Cemental Cracks}

For all laser groups (groups 2-5), greatest number of crack was found in the cementum region. Among all groups, significant difference was found only between groups 2 and $6(\mathrm{p}<0.05)$.

\section{Dentinal Cracks}

Number of cracks was significantly greater in group 1 (ultrasonics) compared with the other groups $(\mathrm{p}<0.05)$. Group 6 (bur) followed group 1, and significantly had more cracks than the other groups, except group $4(\mathrm{p}>0.05)$. Groups 3 and 5 had no crack; thus a significant difference was found between these groups and groups 1, 4 and $6(p<0.05)$. More cracks were seen in group 4 compared to group 2; however, while a tendency for a statistical significance existed, it was not the case $(p>0.05)$.

\section{Canal Wall Cracks}

For all experimental groups, least number of cracks was found in this location. No crack was detected in groups 4 to 6 . No significant difference was found between the experimental groups $(\mathrm{p}>0.05)$.

\section{DISCUSSION}

In recent years, cavity preparation with the use of lasers capable of cutting dental hard tissues has been very popular. ${ }^{12,13}$ The manufacturer of the Er,Cr:YSGG laser device used in this study states that it can be used with a

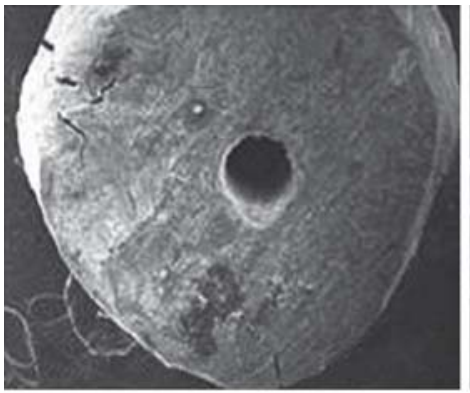

Group 1

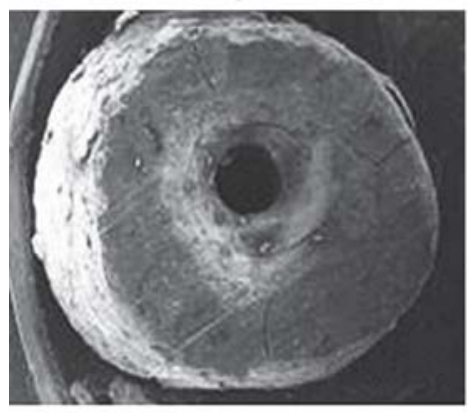

Group 4

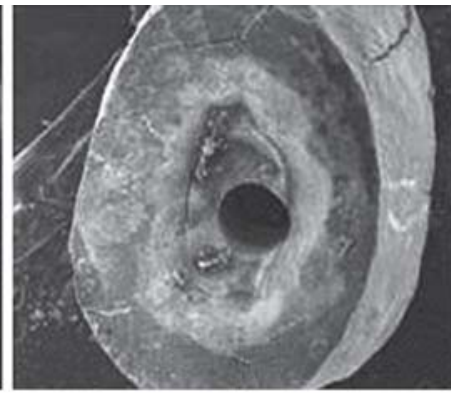

Group 2

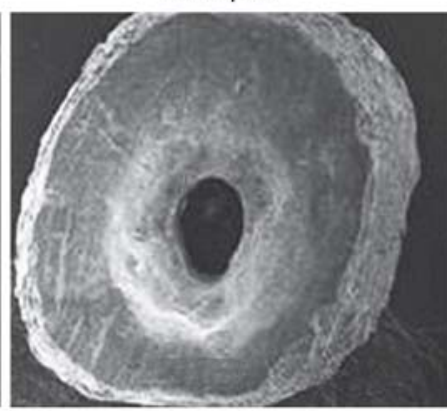

Group 5

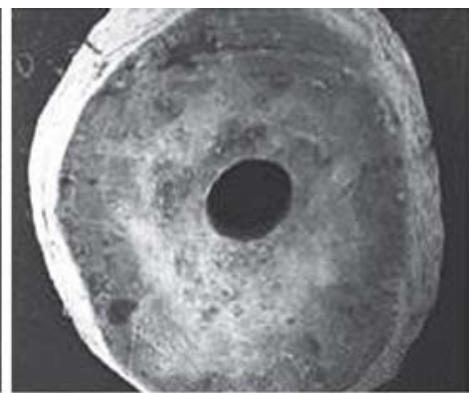

Group 3

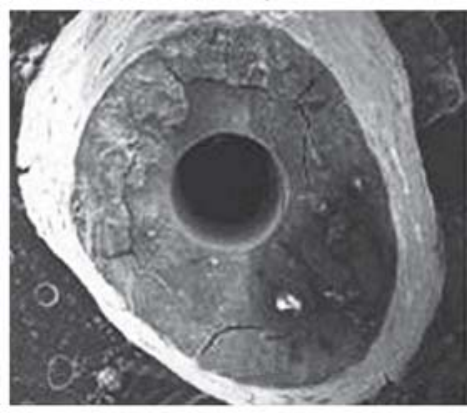

Group 6

Fig. 2: SEM photographs of the six experimental groups ( $\times 25$ magnification). The ablation effect of the laser can be clearly seen in groups 2 to 5 
frequency of 10 to $50 \mathrm{~Hz}$ and 0.1 to $8 \mathrm{~W}$ of power range. It has been reported in studies that if this laser is used under insufficient cooling and with high energy, it causes melting and carbonization on the surface of the dentin and causes crack formation on the root surface. Therefore, determination of the optimal operating parameters of this laser is important. ${ }^{16,19,20}$

Some studies have reported that Er,Cr:YSGG laser causes less crack formation compared to bur and ultrasonic tips on the dentin surface during retrograde cavity preparation. ${ }^{7,11,18}$ However, none of these studies have evaluated the effect of different power and frequency settings during retrograde cavity preparation. Therefore, the Er,Cr:YSGG laser with two different frequencies and two different power settings was tested in this study in order to analyze their effects regarding crack formation on the surface of the root that has been cut prior to testing. Storage conditions and extraction of the teeth used in the study may also cause formation of microcracks on the root surface. For this reason, the teeth used in this study were examined by a stereomicroscope and teeth with cracks were excluded before the study. Also, the teeth were kept in moist condition in order to prevent them from drying. After preparation of the retrograde cavities, formation of cracks was examined by stereomicroscope and one sample from each group was examined with SEM (Fig. 2).

As a result of our study, total crack number that has formed on the surface of the retrograde cavities with ultrasonic tip was found to be greater than the number of cracks caused by the Er,Cr:YSGG laser or bur. This was especially remarkable in the dentin region. This effect might be related to the high frequency vibration that occurred on the surface of the root with the ultrasonic tip. Our finding is in accordance with other studies that has reported that the retrograde cavity preparation with an ultrasonic tip causes more crack formation on the surface of the retrograde cavity than bur and Er,Cr:YSGG laser. ${ }^{17,19}$

\section{Table 1: Crack scores and their distribution (cementum, dentin, canal wall) for the experimental groups [n (\%)]}

\begin{tabular}{|c|c|c|c|c|c|c|}
\hline & Group 1 & Group 2 & Group 3 & Group 4 & Group 5 & Group 6 \\
\hline \multicolumn{7}{|c|}{ Cementum } \\
\hline Score 0 & $4(40)$ & $2(20)$ & $2(20)$ & $3(30)$ & $4(40)$ & $6(60)$ \\
\hline Score 1 & $6(60)$ & $6(60)$ & $8(80)$ & $7(70)$ & $6(60)$ & $4(40)$ \\
\hline Score 2 & $0(0)$ & $2(20)$ & $0(0)$ & $0(0)$ & $0(0)$ & $0(0)$ \\
\hline Score 3 & $0(0)$ & $0(0)$ & $0(0)$ & $0(0)$ & $0(0)$ & $0(0)$ \\
\hline \multicolumn{7}{|l|}{ Dentin } \\
\hline Score 0 & $0(0)$ & $8(80)$ & $10(100)$ & $3(30)$ & $10(100)$ & $2(20)$ \\
\hline Score 1 & $2(20)$ & $2(20)$ & $0(0)$ & 7 (70) & $0(0)$ & $8(80)$ \\
\hline Score 2 & $0(0)$ & $0(0)$ & $0(0)$ & $0(0)$ & $0(0)$ & $0(0)$ \\
\hline Score 3 & $8(80)$ & $0(0)$ & $0(0)$ & $0(0)$ & $0(0)$ & $0(0)$ \\
\hline \multicolumn{7}{|c|}{ Canal wall } \\
\hline Score 0 & $6(60)$ & $6(60)$ & $8(80)$ & $10(100)$ & $10(100)$ & $10(100)$ \\
\hline Score 1 & $4(40)$ & $4(40)$ & $2(20)$ & $0(0)$ & $0(0)$ & $0(0)$ \\
\hline Score 2 & $0(0)$ & $0(0)$ & $0(0)$ & $0(0)$ & $0(0)$ & $0(0)$ \\
\hline Score 3 & $0(0)$ & $0(0)$ & $0(0)$ & $0(0)$ & $0(0)$ & $0(0)$ \\
\hline
\end{tabular}

Table 2: The p-values for binary comparisons of groups. The bold values mean statistical significance

\begin{tabular}{llll} 
& Cementum & Dentin & Canal \\
\hline Group 1 vs group 2 & $\mathrm{p}=0.143$ & $\mathbf{p}<\mathbf{0 . 0 0 1}$ & $\mathrm{p}=1.000$ \\
Group 1 vs group 3 & $\mathrm{p}=0.378$ & $\mathbf{p}<\mathbf{0 . 0 0 1}$ & $\mathrm{p}=0.362$ \\
Group 1 vs group 4 & $\mathrm{p}=0.658$ & $\mathbf{p}=\mathbf{0 . 0 0 6}$ & $\mathrm{p}=0.071$ \\
Group 1 vs group 5 & $\mathrm{p}=1.000$ & $\mathrm{p}<\mathbf{0 . 0 0 1}$ & $\mathrm{p}=0.071$ \\
Group 1 vs group 6 & $\mathrm{p}=0.378$ & $\mathrm{p}=\mathbf{0 . 0 1 7}$ & $\mathrm{p}=0.071$ \\
Group 2 vs group 3 & $\mathrm{p}=0.552$ & $\mathrm{p}=0.429$ & $\mathrm{p}=0.071$ \\
Group 2 vs group 4 & $\mathrm{p}=0.302$ & $\mathrm{p}=0.051$ & $\mathrm{p}=0.071$ \\
Group 2 vs group 5 & $\mathrm{p}=0.143$ & $\mathrm{p}=0.429$ & $\mathrm{p}=0.071$ \\
Group 2 vs group 6 & $\mathbf{p}=\mathbf{0 . 0 2 1}$ & $\mathbf{p}=\mathbf{0 . 0 2 0}$ & $\mathrm{p}=0.362$ \\
Group 3 vs group 4 & $\mathrm{p}=0.658$ & $\mathrm{p}=0.007$ & $\mathrm{p}=0.362$ \\
Group 3 vs group 5 & $\mathrm{p}=0.378$ & $\mathbf{p}=\mathbf{0 . 0 0 2}$ & $\mathrm{p}=0.362$ \\
Group 3 vs group 6 & $\mathrm{p}=0.081$ & $\mathbf{p}=\mathbf{0 . 0 0 7}$ & $\mathrm{p}=1.000$ \\
Group 4 vs group 5 & $\mathrm{p}=0.658$ & $\mathrm{p}=0.692$ & $\mathrm{p}=1.000$ \\
Group 4 vs group 6 & $\mathrm{p}=0.188$ & $\mathrm{p}=\mathbf{0 . 0 0 2}$ & $\mathrm{p}=1.000$ \\
Group 5 vs group 6 & $\mathrm{p}=0.378$ & & \\
\hline
\end{tabular}


The power (W) setting of the laser had little, if any, effect in this study. When groups 2 and $4(3.5 \mathrm{~W}$ and $4 \mathrm{~W}$ power settings, respectively) were compared, only a slight (but insignificant) increase in the number of dentinal cracks was found. When groups 3 and $5(3.5 \mathrm{~W}$ and $4 \mathrm{~W}$ power settings respectively) were compared, again no significant difference was found at the cementum, dentin and canal locations. However, when groups of identical power, but different frequencies were compared (group 2 against 3 and group 4 against 5), a significant difference was found for dentinal cracks; the higher frequency group (group 4, $30 \mathrm{~Hz}$ ) had more cracks in comparison to the low frequency group (group $5.20 \mathrm{~Hz}$ ). From these results, it is deduced that the power setting of $3.5 \mathrm{~W}$ or $4 \mathrm{~W}$ does not make a big difference, but a frequency of $30 \mathrm{~Hz}$ increases the risk of crack. Considering this and viewing the number of cracks shown in Table 1, it is suggested that the safest setting for the laser device is $4 \mathrm{~W}$ at $20 \mathrm{~Hz}$ frequency (group 5). This setting (group 5) also appears to be safer (causes less crack formation) than the ultrasonic group (group 1) and the bur group (group 6), at least in the dentin and canal wall region.

In many of the studies that examined the formation of cracks on the surface of retrograde cavity, it was reported that most of the cracks were seen particularly in the area of cementum. ${ }^{21}$ This may be because the cementum is thinner than dentin in the operatory field. Our study supports this previous finding, as the total number of teeth with cemental, dentinal and canal cracks were 39, 27 and 10 respectively.

\section{CONCLUSION}

Within the limits of this study, it is concluded that ultrasonic root-end preparation is the most aggressive technique. The high frequency $(\mathrm{Hz})$ laser setting, but not the power (W) setting was associated with crack formation. The most favorable laser setting was found to be the one used in group 5; it was generally safer also than the ultrasound and the bur groups.

\section{REFERENCES}

1. Kim S, Kratchman S. Modern endodontic surgery concepts and practice: A review. J Endod 2006;32:601-23.

2. von Arx T, Walker WA 3rd. Microsurgical instruments for rootend cavity preparation following apicoectomy: A literature review. Endod Dent Traumatol 2000;16:47-62.

3. Peters CI, Peters OA, Barbakow F. An in vitro study comparing root-end cavities prepared by diamond-coated and stainless steel ultrasonic retrotips. Int Endo J 2001;34: 142-48.

4. Khabbaz MG, Kerezoudis NP, Aroni E, Tsatsas V. Evaluation of different methods for the root-end cavity preparation. Oral Surg Oral Med Oral Pathol Oral Radiol Endod 2004;98: 237-42.
5. Beling KL, Marshall JG, Morgan LA, Baumgartner JC. Evaluation for cracks associated with ultrasonic root-end preparation of gutta-percha filled canals. J Endo 1997;23: 323-26.

6. Bernardes RA, Moraes IG, Garcia RB, Bernardineli N, Baldi JV, Victorino FR, Vasconcelos BC, Duarte MAH, Bramante CM. Evaluation of apical cavity preparation with a new type of ultrasonic diamond tip. Journal of Endodontics 2007;33:484-87.

7. Lin CP, Chou HG, Kuo JC, Lan WH. The quality of ultrasonic root-end preparation: A quantitative study. J Endo 1998;24: 666-70.

8. De Bruyne MA, De Moor RJ. SEM analysis of the integrity of resected root apices of cadaver and extracted teeth after ultrasonic root-end preparation at different intensities. Int Endo J 2005;38: 310-19.

9. Waplington M, Lumley PJ, Walmsley AD. Incidence of root face alteration after ultrasonic retrograde cavity preparation. Oral Surg Oral Med Oral Pathol Oral Radiol Endod 1997;83: 387-92.

10. Abedi HR, Van Mierlo BL, Wilder-Smith P, Torabinejad M. Effects of ultrasonic root-end cavity preparation on the root apex. Oral Surg Oral Med Oral Pathol Oral Radiol Endod 1995;80: 207-13.

11. Karlovic Z, Pezelj-Ribaric S, Miletic I, Jukic S, Grgurevic J, Anic I. Erbium: YAG laser versus ultrasonic in preparation of root-end cavities. J Endo 2005;31:821-23.

12. Lee BS, Lin PY, Chen MH, Hsieh TT, Lin CP, Lai JY, Lan WH. Tensile bond strength of Er,Cr:YSGG laser-irradiated human dentin and analysis of dentin-resin interface. Dent Materials 2007;23:570-78.

13. Secilmis A, Altintas S, Usumez A, Berk G. Evaluation of mineral content of dentin prepared by erbium, chromium: Yttrium scandium gallium garnet laser. Lasers Med Sci 2008; 23:421-25.

14. Basaran G, Ozer T, Berk N, Hamamci O. Etching enamel for orthodontics with an erbium, chromium: Yttrium-scandiumgallium-garnet laser system. Angle Orthodont 2007;77:117-23.

15. Adu-Arko AY, Sidhu SK, McCabe JF, Pashley DH. Effect of an Er,Cr:YSGG laser on water perfusion in human dentine. Europ J Oral Sci 2010;118:483-88.

16. Hossain M, Kimura Y, Nakamura Y, Yamada Y, Kinoshita JI, Matsumoto K. A study on acquired acid resistance of enamel and dentin irradiated by Er,Cr:YSGG laser. J Clin Laser Med Surg 2001;19:159-63.

17. Noori ZT, Fekrazad R, Eslami B, Etemadi A, Khosravi S, Mir M. Comparing the effects of root surface scaling with ultrasound instruments and Er,Cr:YSGG laser. Lasers Med Sci 2008;23:283-87.

18. Camargo Villela Berbert FL, de Faria-Júnior NB, TanomaruFilho M, Guerreiro-Tanomaru JM, Bonetti-Filho I, Leonardo Rde T, et al. An in vitro evaluation of apicoectomies and retropreparations using different methods. Oral Surg Oral Med Oral Pathol Oral Radiol Endod 2010;110:57-63.

19. Rahimi S, Yavari HR, Shahi S, Zand V, Shakoui S, Reyhani MF. Comparison of the effect of Er,Cr-YSGG laser and ultrasonic retrograde root-end cavity preparation on the integrity of root apices. J Oral Sci 2010;52:77-81.

20. Taschieri S, Testori T, Francetti L, Del Fabbro M. Effects of ultrasonic root end preparation on resected root surfaces: SEM evaluation. Oral Surg Oral Med Oral Pathol Oral Radiol Endod 2004;98:611-18. 
21. Yamazaki R, Goya C, Yu DG, Kimura Y, Matsumoto K. Effects of erbium, chromium: YSGG laser irradiation on root canal walls: A scanning electron microscopic and thermographic study. J Endo 2001;27:9-12.

\section{ABOUT THE AUTHORS}

\section{Seda Arslan (Corresponding Author)}

Specialist, Department of Endodontics, Gazi University, Turkey e-mail: dt.sedarslan@gmail.com

\section{Oya Bala}

Professor, Department of Restorative Dentistry, Gazi University, Turkey

\section{Gizem Berk}

Private Practice, Denta Form Health Center, Turkey

\section{Guven Kayaoglu}

Associate Professor, Department of Endodontics, Gazi University Turkey 